\section{KẾT LUÂN}

Kỹ năng thực hành nghề nghiêp của dược sĩ cộng đồng có mức độ khác biệt ở các quốc gia với mức cao ở quốc gia phát triển và mức thấp ở các quốc gia đang phát triển trong đó có Việt Nam. Những can thiệp hướng đến tập huấn nâng cao và kiểm tra giám sát kỹ năng thực hành nghề nghiệp của dược sĩ cộng đồng cần được quan tâm hơn ở các quốc gia đang phát triển.

\section{TÀl LIÊU THAM KHẢO}

1. Bộ Y tế (2018), "Thông tư số 02/2018/TTT-BYT qưy định về "Thực hành tốt cơ sở bán lẻ thuốc"'.

2. Trân Minh Luẩn, Nguyễn Thanh $\mathbf{V y}$, Nguyễn Thị Thu Thủy (2017), "Đánh giá kỹ năng thực hành nghề nghiêp của người bán lẻ thuốc tai các nhà thuốc đat tiều chuẩn GPP trên địa bàn thành phố Cao Lãnh t tỉnh Đồng Tháp". 492, pp. 2-5.

3. WHO (2018), Tổng quan quốc gia về nhân lực y tế Việt Nam.

4. Collins J. C. et al. (2017), "Management of common ailments requiring referral in the pharmacy: a mystery shopping intervention study", Int J Clin Pharm. 39 (4), pp. 697-703.

5. Eichenberger P. M. et al. (2010), "Classification of drug-related problems with new prescriptions using a modified PCNE classification system", Pharm World Sci. 32 (3), pp. 362-372.

6. Federal.Chamber.of.Pharmacists (2019) Guideline of the Federal Chamber of Pharmacists: Information und Beratung des Patienten bei der Abgabe von Arzneimitteln-Selbstmedikation [Information and counselling of patients during the supply of medicines-self-medication].

7. Hammad E. A. et al. (2018), "A simulated patient study assessing over the counter supply and counseling in Jordan: responding to headache complaints", Int J Clin Pharm. 40 (5), pp. 982-986.

8. Pharmaceutical.Society.of. Australia (2006), Standards for the provision of pharmacy medicines and pharmacist only medicines in community pharmacy.

9. Schumacher P. M. et al. (2019), "Counseling patients on correct drug handling in German community pharmacies: experiences and opinions of pharmaceutical staff", Int J Clin Pharm. 41 (1), pp. 151-158.

10. Seiberth J. M. et al. (2020), "What is the attitude towards and the current practice of information exchange during self-medication counselling in German community pharmacies? An assessment through self-report and non-participant observation", PLoS One. 15 (10), pp. e0240672.

\title{
THỰC TRẬ SÂU RĂNG CỦA SINH VIÊN NĂM THỨ NHẤT TRƯỜ'NG ĐẠI HỌC Y HÀ NộI NĂM HỌC 2020-2021
}

\author{
Hồng Thúy Hạnh¹, Trịnh Minh Báu1, Nguyễn Thị Khánh Huyền',
} Đỗ Sơn Tùng ${ }^{1}$, Đố Hoàng Việt ${ }^{1}$, Phùng Lâm Tới ${ }^{2}$, Hoàng Bảo Duy ${ }^{1}$

\section{TÓM TẮT}

Nghiên cứu mô tả cắt ngang để xác định thực trạng sâu răng được thực hiện trên 770 sinh viên năm thứ nhất trường đải học $Y$ Hà Nôi từ tháng 10 năm 2020 đến tháng 5 năm 2021. Kết quả cho thây: Tỷ lệ sâu răng của sinh viên năm thứ nhất trường đại học Y Hà Nội là $84,55 \%$ trong đó tỷ lệ sâu răng sớm là $62,48 \%$. Chỉ số DMFT là $5,09(D=4,72 ; M=0,04$; $\mathrm{F}=0,33)$. Tỷ lệ sâu răng và chỉ số DMFT đang ở mức cao theo phân loai của WHO.

Ti̛ khóa: sẩu răng, DMFT, sâu răng sớm, sinh viên y, Đại học Y Hà Nội.

\section{SUMMARY \\ DENTAL CARIES STATUS OF FIRST-YEAR STUDENTS HANOI MEDICAL UNIVERSITY}

\footnotetext{
1 Viện Đào tạo Răng Hàm Mặt, trường Đại học Y Hà Nội ${ }^{2}$ Viện Chiến lược và Chính sách Y tế - Bộ Y tế Chịu trách nhiệm chính: Hoàng Bảo Duy Email: drhoangbaoduy@gmail.com Ngày nhận bài: 16.9.2021

Ngày phản biện khoa học: 12.11.2021

Ngày duyệt bài: 22.11.2021
}

IN SCHOOL YEAR 2020 - 2021

A descriptive cross-section in order to determine dental caries status is conducted on 770 first-year students at $\mathrm{Ha}$ Noi Medical University. The results showed that: The total rate of dental caries was $84,55 \%$, of which early dental caries rate was $62,48 \%$. DMFT index: $5,09 \quad(D=4,72 ; M=0,04$; $\mathrm{F}=0,03)$. The rate of dental caries and DMFT index were high according to WHO classification.

Keyword: dental caries, DMFT, early dental caries, medical student, Ha Noi Medical University.

\section{I. ĐĂT VẤN ĐỀ}

Vào những năm 75 của thế kỉ $X X$, tổ chức $y$ tế thế giới (WHO) đã xếp 3 trong số hơn 10 bệnh phổ biến là tai họa của loài người: bệnh tim mạch, bệnh ung thư và bênh sâu răng [1]. Cho đển hiện nay sâu răng vẫn đang là một gánh nặng trong chăm sóc sức khỏe răng miệng toàn cầu. Tỷ lệ sâu răng ở lứa tuổi thanh thiếu niên còn khá cao: cuộc điều tra sức khỏe răng miênng toàn quốc lần 2 năm 2001 của Trần Văn Trường cho thây tỷ lệ sâu răng lứa tuổi 18 là 75,2\%[2], nghiên cứu của Drachev và cộng sự năm 2017 
trên 751 sinh viên đại học $Y$ tại Nga cho thấy tỉ lệ sâu răng đạt 96\%[3]. Lứa tuổi 18-19 là tuổi đang lớn, nhu cầu về thể chất, trí tuệ cũng như vẻ bề ngoài rất cao, đây cũng là thời điểm bộ răng viễn ổn định và hoàn thiện. Sinh viên năm thứ nhất đại học $Y$ với định hướng ngành nghề $Y$ nên có thể có những đặc điểm sâu răng khác biệt. Mặt khác, trong 5 nămm gần đây ít có nghiên cứu về thực trạng sâu răng trên đối tượng này. Từ thực tể đó, tôi thực hiện nghiên cứu này với mục tiêu như sau: Mồ tả tình trạng sâu răng của sinh viên năm thứ nhất trường Đại học Y Hà Nội, năm học 2020-2021.

\section{II. ĐỐI TƯợNG VÀ PHƯƠNG PHÁP NGHIÊN CỨU \\ 1. Đối tượng}

- Tiêu chuẩn lựa chọn: Sinh viên năm thứ nhất trường đại học Y Hà Nội năm học 20202021 có độ tuối 18-19 (sinh năm 2001-2002). Tự nguyện tham gia nghiên cứu.

- Tiêu chuẩn loại trừ: Đối tượng ngoài lứa tuổi 18 -19; đối tượng tại thời điểm khám không đủ sức khỏe để tham gia khám và trả lời câu hỏi khảo sát hoặc đối tượng không hợp tác trong quá trình nghiên cứu.

\section{Thời gian và địa điểm nghiên cứu}

- Thời gian: Từ tháng 10/2020- 5/2021.

- Tại: Viện đào tạo Răng Hàm Mặt, trường đại học Y Hà Nội.

\section{Phương pháp nghiên cứu}

3.1. Thiết kế nghiên cứu: Sử dụng phương pháp nghiên cứu mố tả cắt ngang.

\subsection{Cỡ mẫu:}

Chọn mẫu chủ đích lấy toàn bộ sinh viên năm thứ nhất trường đại học Y Hà Nội. Thực tế chọn được 770 đối tượng phù hợp.

\subsection{Phương pháp thu thập số liệu:}

- Số liệu được thu thập qua bộ câuu hỏi và phiếu khám. Các đối tượng tự trả lời qua bộ câu hỏi thông tin: tuổi, giới, khu vực sống. Tiến hành khám răng miệng ghi vào phiếu khám thông tin chỉ số DMFT theo tiêu chuẩn lố sâu ICDAS [4].

- Người thực hiện quy trình khám là sinh viên răng hàm mặt năm thứ sáu và sinh viên sau đại học trường đại học Y Hà Nội được tập huấn dưới sự hướng dẫn của giảng viền Việ̣n Đào tạo Răng Hàm Mặt trường Đại học Y Hà Nội nhằm thống nhất kĩ năng khám, có trách nhiệm và tuyệt đối tuân thủ quy trình nghiên cứu khoa học.

- Phương pháp khám quan sát kết hợp với thám trâm, gương soi, bóp bóng xì khô và chiếu đèn để phát hiện tổn thương sâu răng, mất răng, tổn thương đã được trám có sâu hay không.

- Cách ghi nhận DMFT:
+ Không ghi nhận răng hàm lớn thứ 3.

+ Răng có nhiều tổn thương sâu thì ghi một tổn thương nặng nhất.

+ Răng có nhiều miếng trám cũng chỉ được ghi nhận 1 lần.

- Tiêu chuẩn ghi nhận chỉ số DMFT dựa theo hướng dẫn của WHO [5].

3.4. Xử lý và phân tích số liệu: Số liệu được xử lý bằng phần mềm Stata 15 và một số thuật toán thống kê: $X^{2}$, Kruskal-Wallis test, Ttest.

\section{KẾT QUẢ NGHIÊN CỨU}

Nghiên cứu được tiến hành trên 770 sinh viên năm nhất đang theo học tại trường Đại học $Y$ Hà Nội, với tỉ lệ nam là $37,4 \%$ và nữ là $62,6 \%$, trong số các sinh viên này có $29,09 \%$ thuộc khu vực 1; 58,44\% khu vực 2; 12,47\% khu vực 3.

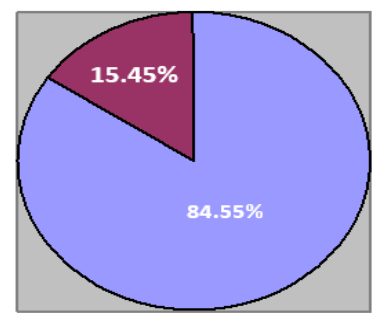

$\square$ sâu răng
$\square$ Không sâu răng

\section{Biểu đồ 1. Tỷ lệ sâu răng của đôî̉ tượng nghiên cứu}

Tỷ lệ sinh viên có sâu răng chiếm 84,55\%.

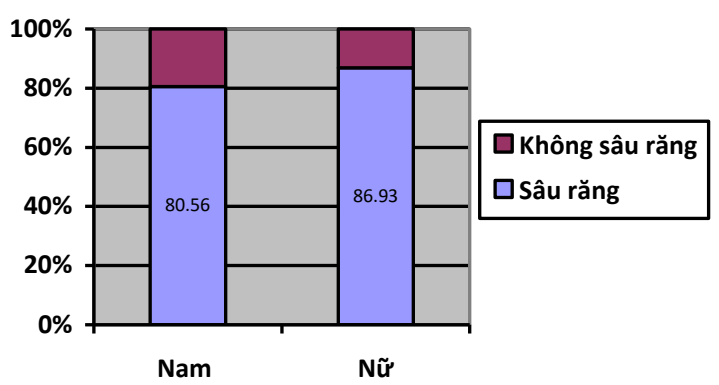

Biểu đồ 2. Tỷ lệ sâu răng theo giới của đôî tượng nghiên cứu

- Tỷ lệ sâu rắng ở nữ $(86,93 \%)$ cao hơn ở nam $(80,56 \%)$.

- Sự khác biệt này có ý nghĩa thống kê với $p$ $(0,018)<0,05$.

Bảng 1: Chỉ số DMFT theo giới của đôi tượng nghiên cứu.

\begin{tabular}{|c|c|c|c|c|}
\hline Giới & $\mathbf{D}$ & $\mathbf{M}$ & $\mathbf{F}$ & DMFT \\
\hline Nam & 4,07 & 0,02 & 0,29 & 4,38 \\
\hline Nữ & 5,11 & 0,05 & 0,33 & 5,49 \\
\hline Tống & $\mathbf{4 , 7 2}$ & $\mathbf{0 , 0 4}$ & $\mathbf{0 , 3 3}$ & $\mathbf{5 , 0 9}$ \\
\hline p & $<0,001$ & 0,304 & 0,034 & 0,316 \\
\hline
\end{tabular}


- Trung bình mỗi sinh viên có 4,72 răng sâu chưa được điều trị, 0,04 răng mất do sâu và 0,33 răng sâu đã được trám.

- Chỉ số sâu răng ở nữ $(5,11)$ cao hơn ở nam $(4,07)$ và sự khác biệt này có ý nghĩa thống kê với $p<0,001$.

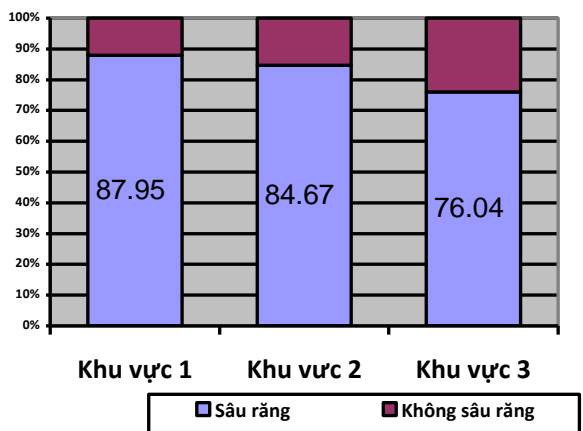

Biểu đồ 3. Tỷ lệ sâu răng theo khu vực của đôi tương nghiên cứu.

- Tỷ lê sâu răng cao nhất ở khu vực $1(87,95 \%)$, thấp nhất là khu vực $3(76,04 \%)$. Sự khác biệt có ý nghĩa thống kê với $p<0,05$.

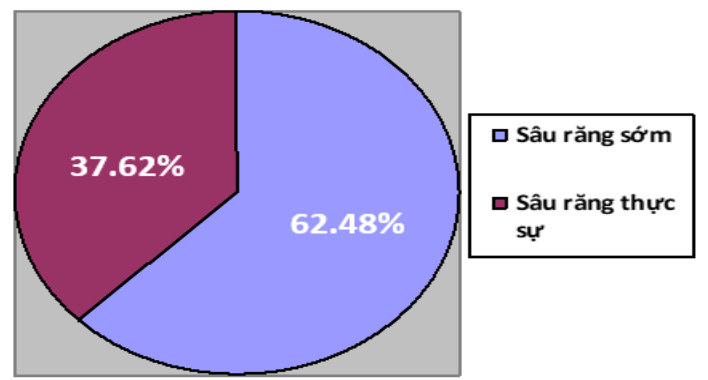

Biểu đồ 4. Tỷ lệ sâu răng sớm.

- Trong 770 sinh viên tham gia nghiên cứu có 3539 răng sâu trong đó có 2211 răng sâu sớm chiếm $62,48 \%$.

Bảng 2: Chỉ số DMFT theo khu vực của đôî tượng nghiên cứu

\begin{tabular}{|c|c|c|c|c|}
\hline Khu vực & D & M & F & DMFT \\
\hline KV1 & 4,85 & 0,058 & 0,42 & 5,33 \\
\hline KV2 & 4,69 & 0,029 & 0,3 & 5,02 \\
\hline KV3 & 4,58 & 0,041 & 0,26 & 4,88 \\
\hline Tống & 4,72 & 0,04 & 0,33 & 5,09 \\
\hline p & 0,378 & 0,109 & 0,63 & 0,14 \\
\hline
\end{tabular}

Chỉ số sâu răng (D), mất răng do sâu (M), răng sâu đã được trám( $F)$ và chỉ số sâu mất trám (DMFT) ở 3 khu vực có khác biệt nhưng sự khác biệt này không có ý nghĩa thống kê với $\mathrm{p}>0,05$.

\section{BÀN LUÂN}

Từ biểu đồ 1 cho thấy tỷ lệ sâu răng chung của nhóm đối tượng nghiên cứu là $84,55 \%$. Tỉ lệ sâu răng ở mức cao theo phân loại của WHO
(1997). So với các nghiên cứu trong và ngoài nước khác thấy được kết quả này tương đồng với nghiên cứu của Drachev năm 2017 trên sinh viên 449 sinh viên $Y$ khoa và 309 sinh viên nha khoa tại Nga [3] (tuổi 18-20: 94,9\%) hay nghiên cứu của Ngô Thị Thu Hà năm 2016 trên 288 sinh viên Y Hà Nội năm thứ nhất [6](78.1\%). Tuy nhiên kết quả này lại cao hơn so với nghiên cứu của Hà Thị Nga năm 2015 trên 364 sinh viên Y Hà Nội năm thứ nhất [7] $(49,2 \%)$, điêu này có thể do tiêu chí đánh giá răng sâu của trong nghiên cứu này có điểm mới, đánh giá răng sâu dựa trên phân loại sâu răng ICDAS, đánh giá răng sâu từ giai đoạn sớm, khi tổn thương còn chưa hình thành lỗ sâu thực sự còn tác giả đánh giá dựa theo hướng dẫn của WHO (1997) [1] ghi nhận tổn thương sâu khi có lỗ sâu thực sự.

Tỷ lệ sâu răng có sự khác biệt có ý nghĩa thống kê ở hai giới, trong đó tỷ lệ sâu răng của sinh viên nữ cao hơn là $86,93 \%$, ở sinh viên nam là $80,56 \%$. Kết quả này giống với một số nghiên cứu trong và ngoài nước khác như nghiên cứu của Ngô Thị Thu Hà (2016) (nữ: 84\%; nam 70,6\%) [6] nghiên cứu của Drachev (2017)( nữ $: 96,3 \%$; nam 95,2\%) [2]. Điều này có thể do sự khác biệt về thay đổi hormone lứa tuổi dậy thì có sự khác nhau giữa hai giới.

Sinh viên nông thôn và miền núi có tỷ lệ sâu răng cao hơn (khu vực 1 là 87,95\%; khu vực 2 là $84,67 \%)$ sinh viên thành phố $(76,04 \%)$. Tương đồng với nghiên cứu của Ngô Thị Thu Hà năm 2016 [6] (thành phố: 68,3\%; nông thôn: 80,9\%) hoặc nghiên cứu của Drachev năm 2017 [4]: tỷ lệ sâu răng sinh viên ở thành phố là $95,5 \%$, sinh viên ở nông thôn là $97,2 \%$ [3]. Điều này có thể do các điều kiên kinh tế xã hội khác nhau dẫn đến việc tiếp cận các chương trình giáo dục sức khỏe răng miệng, thăm khám và chữa bênh còn chưa phủ khắp. Các em sinh viên thành phố có nhiều điều kiên tiếp xúc với các chương trình khám chữa bệnh cộng đồng, có nhiều cơ sở khám chữa bệnh nhà nước cũng như phòng khám tư nhân để lựa chọn và điều kiện kinh tế của gia đình cũng cho phép các em có thể chi trả cho các dịch vụ chăm sóc răng miệng.

Về tỉ lệ sâu răng sớm, biểu đồ 4 cho thấy: Trong số 770 sinh viên tham gia nghiên cứu có 3539 răng sâu, trong đó số răng sâu sớm là 2211 chiếm $62,48 \%$, số răng đã hình thành lỗ sâu thực sự là 1328 chiếm 37,62\%. Như vậy đa phần số răng sâu trong nghiên cứu là sâu răng sớm. Với những tổn thương sâu răng sớm này có thể điều trị tái khoáng hóa bằng các sản phẩm có chứa fluor như kem đánh răng, vecni fluor, 
gel fluor..., hoặc với những răng có hố rãnh phức tạp có thể tiển hành trám bít hố rãnh để dự phòng sâu răng.

Nghiên cứu của chúng tôi cho kết quả với chỉ số sâu mất trám của nhóm đối tượng nghiên cứu là 5,09; ở mức cao theo phân loại của WHO (4,5$6,5)$. Trung bình mỗi người có 4,72 răng sâu; 0,04 răng mất do sâu; 0,33 răng sâu đã được trám. Trong đó chỉ số răng được trám $(T)$ thấp hơn nhiều so với chỉ số sâu răng (D), điều này phản ánh mức độ điều trị sâu răng còn chưa cao. Chỉ số DMFT ở giới nữ là 5,49 ở mức cao $(4,5-6,5)$ và giới nam là 4,38 ở mức trung bình $(2,7-4,4)$. Tuy nhiên có thể thấy rằng chỉ số sâu răng (D) ở nữ cao hơn ở nam còn chỉ số mất răng do sâu (M) và răng sâu được trám $(F)$ không có sự chênh lệch rõ ràng. So sánh với nghiên cứu của Ngô Thị Thu Hà [6], Hà Thị Nga [7], thấy rằng nghiên cứu này cũng cho chỉ số DMFT cao hơn và tập trung chủ yếu sự chênh lệch do cao hơn ở chỉ số sâu răng. Điều này có thể là do nghiên cứu của chúng tôi với cỡ mấu lớn hơn (770 sinh viên) và sử dụng tiêu chí đánh giá răng sâu theo phân loại ICDAS [4] còn tác giả sử dụng phân loại của WHO(1997) [1].

Chỉ số DMFT giảm dần từ khu vực 1 đến khu vực 3. Từ kiểm định thống kê cho thấy không có sự khác biệt có ý nghĩa giữa các khu vực sống. Điều này giống với một số nghiên cứu của Ngô Thị Thu Hà năm 2016 [6] Điều này có thể giải thích rằng đối tượng của nghiên cứu này đang ở lứa tuổi thanh thiếu niên với bộ răng vĩnh viễn và sự tích lũy sâu răng chưa đủ để gây ra sự khác biệt giữa các khu vực sống.

\section{KẾT LUÂNN}

Tỷ lệ sẩu răng của nhóm đối tượng nghiên cứu là $84,55 \%$ ở mức cao chủ yếu là sâu răng sớm. Trong đó tỷ lệ sâu răng ở nữ cao hơn ở nam, tỷ lệ sâu răng ở khu vực 1 cao hơn khu vực 2 và cao hơn khu vực 3 . Chỉ số DMFT của nhóm đối tượng nghiên cứu là 5,09, ở mức cao trong đó ở nữ cao hơn ở nam và khu vực 1 , khu vực 2 thì lớn hơn khu vực 3 . Từ kết quả nghiên cứu, những khuyến cáo và đề xuất có thể được đặt ra để gứi tới nhà trường và đối tượng nghiên cứu để có sự cải thiện và thay đổi tình trạng sâu răng.

\section{TÀI LIÊUU THAM KHẢO}

1. WHO (1997), Oral health survey, basic method,

2. Trân Văn Trường và CS (2001). Điêu tra sức khỏe răng miệng toàn quốc,. nhà xuất bản $Y$ học, 22-70.

3. Drachev, S. N., Brenn, T., \& Trovik, T. A. (2017), Dental caries experience and determinants in young adults of the Northern State Medical University, Arkhangelsk, North-West Russia,

4. Ismail Ai , Sohn $W$, Tellez M, Amaya A, Sen $A$, Hasson $\mathrm{H}$ et al. (2007). The International Caries Detection and Asseessment Syste (ICDAS): an integrated system for measuring dental caries. Community Dent Oral Epidemiol.

5. WHO (2013), Oral health survey, basic method, World Health Organization.

6. Ngô Thị Thu Hà (2016). Thực trang sâu răng, nhu câu điều trj và một số yếu tố ảnh hưởng tới bệnh sâu răng của sinh viên năm thứ nhất đại học Y Hà Nội năm học 2015-2016. trường đại học Y Hà Nội.

7. Hà Thị Nga (2015). Thực trạng sầu răng và liền quan giữa thói quen chăm sóc răng miệng với sâu răng của sinh viên $y 1$ trường đại học $Y$ Hà Nội năm học 2014-2015. trường đại học Y Hà Nội, 31-49.

\section{KẾT QUẢ ĐIỀU TRỊ GÃY KÍN ĐẦU DƯớI XƯƠNG ĐÙI BÂNG NEP KHÓA Ở NGƯỜI TRƯỞNG THÀNH TẠI BỆNH VIÊ̂N TRUNG ƯƠNG THÁI NGUYÊN}

\author{
TÓM TẮT.
}

Tạ Văn Công1, Trần Chiến ${ }^{1}$ Hoàng Văng Dung ${ }^{2}$, Nguyễn Ngọc Sơn ${ }^{2}$

Đặt vấn đề: Gãy đầu dưới xương đùi là một gãy xương lớn, phức tạp, thường ảnh hưởng đến chức năng vận động của khớp gối. Nepp khóa đầu dưới xương đ̛̣ùi giúp cố định vững chắc ổ gãy theo cấu trúc giải phẩu, bệnh nhân tập vận động sớm șau mổ. Mưc tiêu nghiên cứu: Đánh giá kết quả phẫu thuật điểu trị gãy kín đầu dưới xương đùi bằng nẹp khóa ở người trưởing thành. Đối tượng và phương pháp nghiên cứu: Nghiên cứu mô tả cắt ngang. Từ tháng 1 năm 2018 đển tháng 6 năm 2021, 33 bệnh nhân trong độ tuổi từ 18 tuổi trở lên gãy kín đầu dưới xương đưi được phẫu thuật kết hợp xương bằng nẹp khóa. Thời 